\title{
The Effect of Leptospirosis Prevalence in Cows and Its Relation to Human Population during the Past Decades (2003-2013) in Gilan Province
}

\author{
Ebrahim Rahimabadi ${ }^{1}$, Yadollah Asadpour $^{* *}$, Hamed Kiomarsi ${ }^{2}$ \\ ${ }_{1}^{1}$ Razi Vaccine and Serum Research Institute, Agricultural Research, Education and Extension Organization (AREEO), Karaj, Iran \\ ${ }^{2}$ Animal Science Research Department, Gilan Agricultural and Natural Resources Research and Education Center (AREEO), Rasht, \\ Iran
}

\section{*Corresponding Author}

Yadollah Asadpour

\section{Article History}

Received: 26.09.2019

Accepted: 03.10.2019

Published: 21.11.2019

\begin{abstract}
Background: Leptospirosis is one of the most important contagious zoonosis diseases caused by different serovars of Leptospira interrogans. Objectives: The aim of the present study is to determine the prevalence rate of Leptospira pathogen serovars in cows and relation to human population in Gilan province during 2003-2013. Methods: Totally 1250 serum samples were collected from different cities in Gilan (800 samples at 2003 and 450 samples at 2013 from cows). The serum samples were analyzed employing the Microscopic Agglutination Test (MAT) at the Razi Research Institute Center. Results: The infection rate was high, in 34 years old cows and in spring seasons. In 2013, serum samples showed a positive reaction against leptospira which was higher compared to 2003. The most seroprevalent serovar was Grippotyphosa and the least was serovar Canicola in 2003 and predominant seroprevalent was Icterohaemprragia and the least was Pomona in 2013. The most percentage rates of MAT titers were 1:200 in 2003, and most percentage rates of MAT titers were 1:800 and1:1600 in 2013. The infection rate was high and according to the review of Leptospirosis prevalence in cows and its relation to the human population between 2003 and 2013. The relationship between human infection and an increase in animal titer with the highest rate of infection seen in the countryside. Conclusions: There is an important concern about the possibility of the occurrence of an acute form of the disease with low prevalence. There is, therefore, a need to control the disease in Gilan Province.
\end{abstract}

Keywords: Leptospirosis, Gilan, Cows, Human population, MAT.

\section{INTRODUCTION}

Leptospirosis is one of the most widespread zoonoses and represents a major threat to human health. In fact, it is a typical example of a disease that will require a joint collaboration between human medical and veterinary medical communities, if public health is to be maintained. Leptospirosis occurs worldwide with highest burden in low-income populations living in tropical and subtropical regions, both in urban and in rural environments [1]. Humans can become infected through contact with urine or other body fluids (except saliva) from infected animals. However, the source of infection in humans is usually contacted with the urine of infected animals. The bacteria can enter the body through the skin or mucous membranes, especially if the skin is broken from a cut or scratch. Drinking contaminated water can also cause infection. Person to person transmission is rare. It is observed that the infection rate is higher among athletes and also men compare to the women [2,3]. Many different kinds of wild and domestic animals carry the bacterium. These can include but are not limited to: cattle, pigs, horses, dogs, rodents, wild animals [4]. When these animals are infected, they may have no symptoms of the disease. However, infected animals may continue to excrete the bacteria into the environment continuously or every once in a while for a few months up to several years. Hochedez et al. [5] conducted research to identify factors associated with disease severity, they examined 102 patients and high levels of leptospiremia, and infection with $\mathrm{L}$. Interrogans serovar Icterohaemorrhagiae/Copenhagen were observed. The results also revealed the potential correlation between disease severity and serogroup icterohaemorrhagiae. However, there have been other researchers by the scientist on this area which emphasizes the need for public health action to control infection $[6,7,4,5,8]$. However, the data still does not seem to be adequate. At this research, we conduct to determine the prevalence rate of Leptospira pathogen serovars in cows and Relation to Human Population in Gilan province during 2003 - 2013.

Copyright @ 2019: This is an open-access article distributed under the terms of the Creative Commons Attribution license which permits unrestricted use, distribution, and reproduction in any medium for non commercial use (NonCommercial, or CC-BY-NC) provided the original author and source are credited. 


\section{Materials and Methods}

For this study, a total of 1250 serum samples (800 samples at 2003 and 450 samples at 2013) were randomly collected from cows of smallholder dairy farms in nine different areas of Gilan Province where there was not vaccination program against leptospirosis. The microscopic agglutination test (MAT) is designated the "gold standard" for the laboratory diagnosis of leptospirosis, in this method, blood serum separate immediately at $4^{\circ} \mathrm{C}, \mathrm{A}$ dilution series of the patient's serum is mixed with a different titer suspension of live leptospires in microtiter plates. After incubating for about $2 \mathrm{hr}$ at $30^{\circ} \mathrm{C}$, results are read under the dark-field microscope. The MAT was carried out at the leptospira Research Laboratory of the Razi Vaccine and Serum Research Institute in Karaj. The serum samples were tested for antibody to leptospira serovars Grippotyphosa, Pomona, Icterohaemorrhagiae, Canicola and Hardjo $[9,10]$.

\section{Sample size}

According to the Iran Veterinary Organization (IVO) report which stated the least prevalence was 10 percentage and using the following formula, the sample size of 500 was determined: $\mathrm{N}=\mathrm{Z}^{2} \times \mathrm{S}^{2} / \mathrm{d}^{2}$

\section{RESULTS}

The results are provided in Tables and Figures 1 to 5 . The results illustrated that in $2003,22.75 \%$ samples showed a positive reaction against leptospira and $88.64 \%$ of serum samples showed a positive reaction against only one leptospira serovars. However, the most seroprevalent serovar was serovar Grippotyphosa $(37.43 \%)$ and the least was serovar Canicola $(6.16 \%)$; the other commonly reacting serovars being leptospira serovars Icterohaemprragia (23.52\%), Pomona (11.80\%) and Serjohardjo $(21.02 \%)$.

The results of MAT on serum samples demonstrated 1:200 (45.9\%), 1:400 (32.36\%), 1:800 (14.0\%), 1:1600 (4.84\%), 1:3200 (2.9\%) and 1:6400 (0\%). In 2013, serum samples showed a positive reaction against leptospira (31.7\%). The results revealed that $81.7 \%$ of serum samples were positive to only one leptospira serovars while $18.3 \%$ more than one spp.

The percentage rate of leptospira serovars were including: Grippotyphosa (17.6\%), Icterohaemprragia (49.3\%), Pomona $(1.4 \%)$, Serjohardjo (26.1\%) and Canicola (5.6\%). The Percentage rate of MAT titers were 1:200 (0.7\%), 1:400 (21.1\%), 1:800 $(30.3 \%), 1: 1600(29.6 \%), 1: 3200(14.8 \%), 1: 6400(3.5 \%)$. The results also revealed that prevalence rate to leptospirosis was higher in $3-4$ years old cow $(29 \%)$ and spring season $(37.5 \%)$.

Table-1: The serum of animals infected with leptospira serovars

\begin{tabular}{|c|c|c|c|}
\hline Samples & Negative & Positive & Years of sampling \\
\hline 450 & $68.4 \%$ & $31.6 \%$ & 2013 \\
\hline 800 & $77.15 \%$ & $22.75 \%$ & 2003 \\
\hline
\end{tabular}

There was a significant difference between Past Decades $(p=0.5)$

Table-2: The serum of animals infected with leptospira serovars

\begin{tabular}{|c|c|c|c|}
\hline Addition & $\begin{array}{c}\text { Positive } \\
\text { to one serotype }\end{array}$ & $\begin{array}{c}\text { Positive } \\
\text { to one serotype }\end{array}$ & Years of sampling \\
\hline 100 & $18.3 \%$ & $81.7 \%$ & 2013 \\
\hline 100 & $11.54 \%$ & $88.46 \%$ & 2003 \\
\hline
\end{tabular}

Table-3: The serum of animals infected with different leptospira serovars

\begin{tabular}{|c|c|c|c|c|c|}
\hline Canicol a & Serjohardjo & Pomona & Icterohaemprragia & Grippotyphosa & Years of sampling \\
\hline $5.6 \%$ & $26.1 \%$ & $1.4 \%$ & $49.3 \%$ & $17.6 \%$ & 2013 \\
\hline $6.16 \%$ & $21.02 \%$ & $11.8 \%$ & $23.52 \%$ & $37.43 \%$ & 2003 \\
\hline \multicolumn{7}{|c|}{ There was a significant difference between Icterohaempragia in Past Decades $(\mathrm{p}=0.47)$} \\
\hline
\end{tabular}

Table-4: Positive reaction of animal's serum to Leptospira infectious titer

\begin{tabular}{|c|c|c|c|c|c|c|}
\hline $1: 6400$ & $1: 3200$ & $1: 1600$ & $1: 800$ & $1: 400$ & $1: 200$ & Years of sampling \\
\hline $3.5 \%$ & $14.8 \%$ & $29.6 \%$ & $30.3 \%$ & $21.1 \%$ & $0.7 \%$ & 2013 \\
\hline 0 & $2.9 \%$ & $4.84 \%$ & $14 \%$ & $32.36 \%$ & $45.9 \%$ & 2003 \\
\hline
\end{tabular}

There was a significant difference between Past Decades $(p=0.5)$ 
Table-5: Distribution of leptospirosis cases in terms of season

\begin{tabular}{|c|c|c|c|}
\hline Percent & Positive & Sample & Season \\
\hline 43 & 52 & 120 & Spring \\
\hline 19.5 & 22 & 112 & summer \\
\hline 28.5 & 30 & 105 & Autumn \\
\hline 33.5 & 38 & 113 & Winter \\
\hline 31.6 & 142 & 450 & Total \\
\hline
\end{tabular}

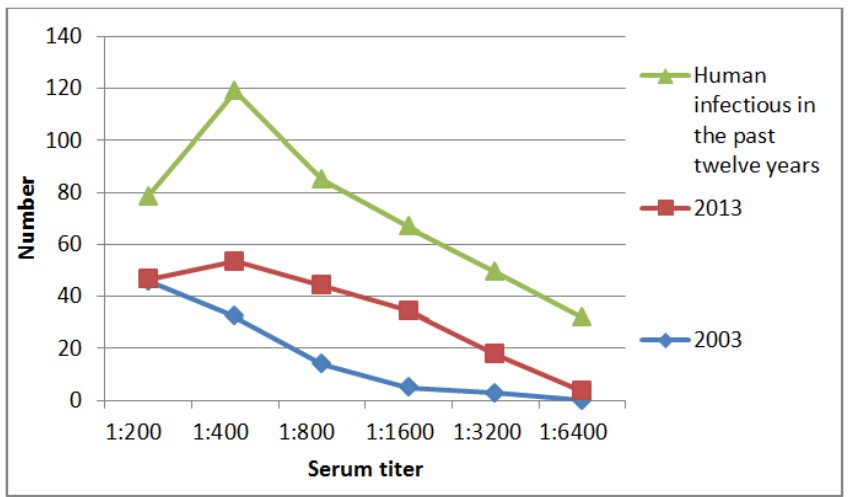

Fig-1: Distribution of leptospira serovars cases in terms of serum titer

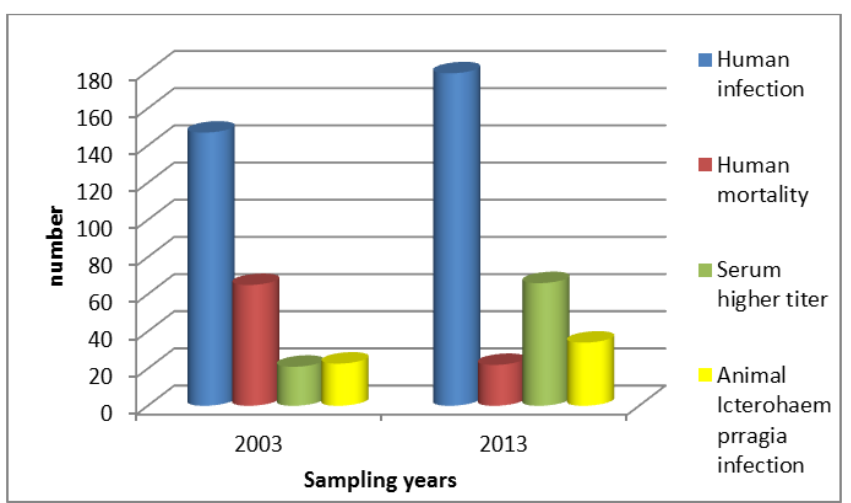

Fig-2: Distribution of leptospirosis cases according to different decades

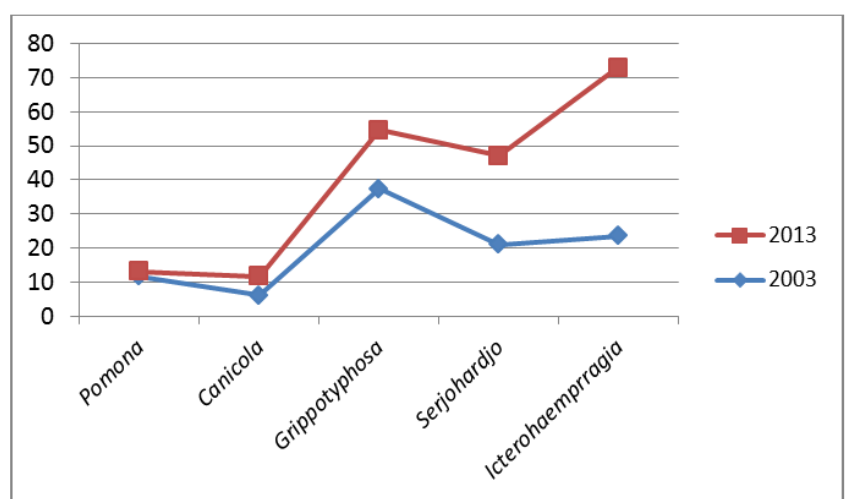

Fig-3: Distribution of different leptospira serovars according to different decades 


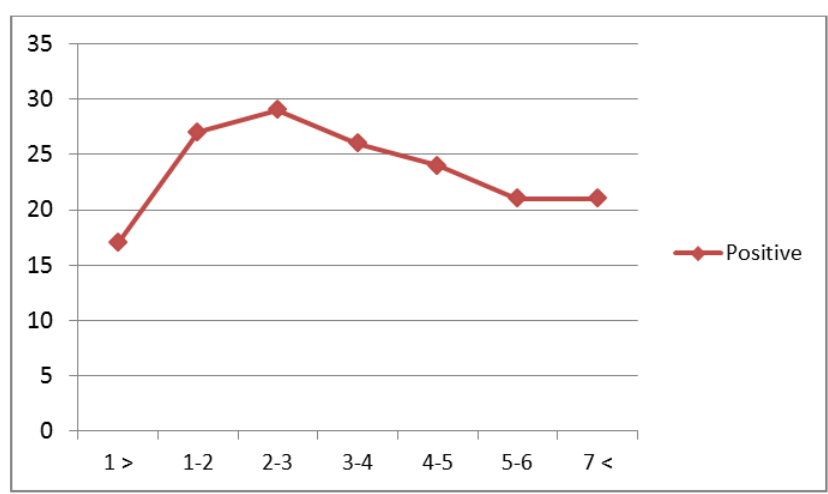

Fig-4: Distribution of leptospira serovars cases in animals in terms of age

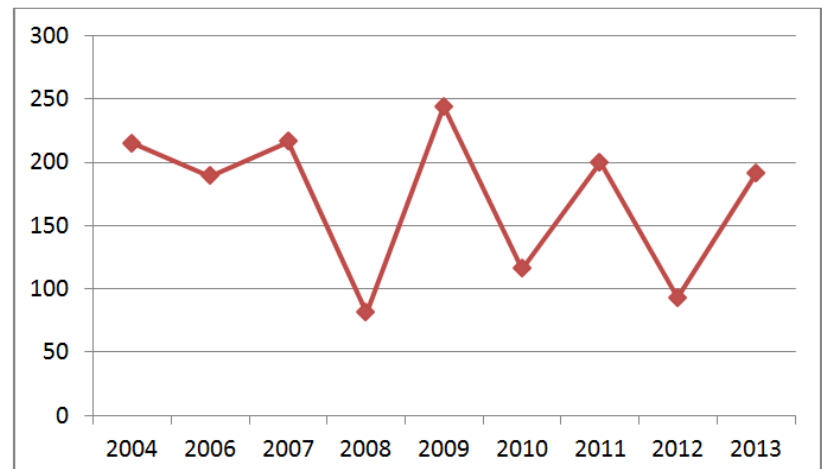

Fig-5: Distribution of leptospira serovars cases in humans in Gilan province from 2003 to 2013

\section{Discussion}

In this research the infection rates to seroprevalence of leptospirosis was high in the Gilan Province, which is in line with results observed by other researchers which indicates the high infection rate in the country and specifically in the North of Iran [2, 3]. Babamahmodi et al. [2] states that people in the North of Iran are mostly involved in agriculture and farming and leptospirosis is common in this area. In fact, they conducted research on a population of 500 people that were involved in one of the four mentioned high-risk occupations for leptospirosis.

Ebrahimi et al. [6] made a serological survey of human leptospirosis in tribal areas of West Central Iran. The results revealed that from 400 Samples, 194 Samples (48.5\%) were positive to different leptospiral serovars at a minimum titer of 1:100. They highlighted the geographical factors as a key element in infection distribution.

The results of the current study showed a relationship between human infection as well as an increase in animal titer and seroprevalence of Icterohaemorrhagiae. However, the highest rate of infection was observed in the countryside. The results also revealed a decrease in human mortality due to increasing knowledge about the disease in the province. The results were in line with previous studies which showed the highest amount of infection in the rural areas and in the male [11] aged between 20-40 and also in the rainy seasons and mostly in the people who were mostly in contact with animal and also the infection rates were higher in farmers $[4,12]$. The results also revealed that the infection rates were at its highest point during the spring (March until May) caused by increased rainfall and standing water/flooding, which is in line with the results reported in some previous studies [3, 13]. It was also at its lowest points during the summer which could be justified because it's the rice farming season and farmers tend to keep their livestock from the farms and it could lead to decrease in the spread of the disease. However, the main cause of the disease is transmitted to humans through environmental surface waters contaminated by the urine of chronically infected mammals, lack of adequate sanitation and poor housing also increases the risk of exposure to leptospires [14]. However, infection is documented yearround $[15,16]$. In general, the identified seroprevalence rates and the higher number of Icterohaemorrhagiae amongst them are in line with previous studies $[13,16,17]$. However, it can be concluded that there is a real need to control and fight against the infection in Gilan Province.

\section{REFERENCES}

1. Goarant, C. (2016). Leptospirosis: risk factors and management challenges in developing countries. Research and reports in tropical medicine, $7,49$. 
2. Babamahmodi, F., Motamed, N., Mahdavi, M. R., Nickhah, F., \& Qavi Bonyeh, K. H. (2006). Seroepidemiological study of leptospirosis in Ghaemshahr Mazandaran province-Iran, Sept-Oct 2004. Journal of Mazandaran University of Medical Sciences, 16(53), 51-56.

3. Pappas, G., Papadimitriou, P., Siozopoulou, V., Christou, L., \& Akritidis, N. (2008). The globalization of leptospirosis: worldwide incidence trends. International journal of infectious diseases, 12(4), 351-357.

4. Honarmand, H. (2009). A decade, the incidence of leptospirosis in Guilan. Iranian Journal of Infectious Diseases, 47, 47-53.

5. Hochedez, P., Theodose, R., Olive, C., Bourhy, P., Hurtrel, G., Vignier, N., \& Herrmann, C. (2015). Factors associated with severe leptospirosis, Martinique, 2010-2013. Emerging infectious diseases, 21(12), 2221.

6. Ebrahimi, A., Alijani, L., \& Abdollahpour, G. R. (2015). Serological survey of human leptospirosis in tribal areas of west central Iran. Iranian Journal of Medical Sciences, 28(2), 93-95.

7. Hakke, D. A., \& Levett, P. N. (2015). Leptospirosis in humans. In Leptospira and leptospirosis. Springer, Berlin, Heidelberg, 6597

8. Peters, A., Vokaty, A., Portch, R., \& Gebre, Y. (2018). Leptospirosis in the Caribbean: a literature review. Revista Panamericana de Salud Pública, 41, e166.

9. Romero, E. C., Caly, C. R., \& YASUDA, P. H. (1998). The persistence of leptospiral agglutinins titers in human sera diagnosed by the microscopic agglutination test. Revista do Instituto de Medicina Tropical de Sao Paulo, 40(3), 183-184.

10. Chappel, R. J., Goris, M., Palmer, M. F., \& Hartskeerl, R. A. (2004). Impact of proficiency testing on results of the microscopic agglutination test for diagnosis of leptospirosis. Journal of clinical microbiology, 42(12), 5484-5488.

11. Guerra-Silveira, F., \& Abad-Franch, F. (2013). Sex bias in infectious disease epidemiology: patterns and processes. PloS one, 8(4), e62390.

12. Perrocheau, A., \& Perolat, P. (1997). Epidemiology of leptospirosis in New Caledonia (South Pacific): a one-year survey. European journal of epidemiology, 13(2), 161-167.

13. Vandeyosefi, G., Moradibidhendi, S., \& Ameli M. (1996). Investigation of cow and sheep Leptospirosis and detection of disease contaminated zone in Iran saspected area. Razi institute archive. Final report.

14. Felzemburgh, R. D., Ribeiro, G. S., Costa, F., Reis, R. B., Hagan, J. E., Melendez, A. X., \& Silva, A. Q. (2014). Prospective study of leptospirosis transmission in an urban slum community: role of poor environment in repeated exposures to the Leptospira agent. PLoS neglected tropical diseases, 8(5), e2927.

15. Hajikolaei, M. R. H., Haidari, M. M., \& Abdollapour, G. O. L. A. M. R. E. Z. A. (2005). Comparison of leptospiral infection in the horse and donkey. Bull Vet Inst Pulawy, 49, 175-178.

16. Khaki, P., \& Moradibidhendi, S. (2005). Prevalence of Leptospirosis in Iran. 4th Scientific Meeting of International Leptospirosis Society, 11 Sep, Iran. 179.

17. Wunder, E.A., Eshghi, A., \& Benaroudj, N. (2018). Pathogenesis of Leptospira. Front. Cell. Infect. Microbiol, 8(1): 322. 